\title{
O Trabalho como Potencialidade Subjetiva na Experiência Migratória
}

\author{
Cristiano Dal Forno* \\ Pontifícia Universidade Católica do Rio Grande do Sul - PUC-RS, Porto Alegre, RS, Brasil \\ ORCID: https://orcid.org/0000-0002-5299-7485 \\ Rita de Cássia dos Santos Canabarro** \\ Universidade Federal do Rio Grande do Sul - UFRGS, Porto Alegre, RS, Brasil \\ ORCID: https://orcid.org/0000-0003-3488-4281 \\ Mônica Medeiros Kother Macedo*** \\ Universidade Federal do Rio Grande do Sul - UFRGS, Porto Alegre, RS, Brasil \\ ORCID: https://orcid.org/0000-0001-9347-8537
}

\begin{abstract}
RESUMO
A busca por oportunidades de trabalho profissional que permitam aos sujeitos melhores condições de vida está diretamente relacionada às migrações internacionais. $\mathrm{O}$ trabalho profissional afigura-se como recurso potencializador de saúde psíquica ao promover a experiência de reconhecimento de capacidades do migrante, com efeitos em sua subjetividade. Por meio do método de pesquisa psicanalítica, este artigo discorre sobre o papel do trabalho profissional frente aos impasses da vivência migratória. Discutem-se os riscos à tendência de patologização social da migração e aborda-se a relação entre migração e potencialidades criativas da prática laboral. Entrevistou-se um migrante haitiano e se elegeu, também, como material de análise, o livro intitulado "Sonhos que mobilizam o imigrante haitiano: biografia de Renel Simon". No testemunho constituído a partir da análise dessas narrativas, elabora-se o modo particular com que cada um destes sujeitos tem enfrentado seus desafios no caminho do trabalho de migrar. Conclui-se que o trabalho profissional responde à dimensão identitária, aquilatando o valor de si mesmo, na medida em que possibilita ao sujeito sua inserção social e vivências intersubjetivas de reconhecimento pelas atividades realizadas.
\end{abstract}

Palavras-chave: migração, diáspora haitiana, subjetividade, psicanálise, trabalho.

\section{Work as Subjective Potentiality in the Migratory Experience}

\begin{abstract}
The search for professional work opportunities which allow the subjects better living conditions is directly related to international migration. Professional work seems to be a resource which enhances psychic health by promoting the experience of recognition of the migrant's skills, with effects on their subjectivity. Through the method of psychoanalytic research, this article examines the role of professional work in relation to the impasses of migratory experience. The risks to the social pathologization of migration tendencies are discussed and the relationship between migration and the creative potential of labor practice is approached. A Haitian migrant was interviewed and the book entitled "Sonhos que mobilizam
\end{abstract}


o imigrante haitiano: biografia de Renel Simon" (Dreams that mobilize the Haitian immigrant: A biography of Renel Simon) was also selected as a research material. In a statement constituted from the analysis of these narratives, the individual way of how each one of these subjects has faced challenges along the migration process has been explained. The article concludes that professional work responds to the identity dimension, assessing value of one-self, as it allows the subject in its social insertion and intersubjective experiences of recognition for the activities performed.

Keywords: migration, Haitian diaspora, subjectivity, psychoanalysis, work.

\section{EI Trabajo como Potencialidad Subjetiva en la Experiencia Migratoria}

\section{RESUMEN}

La búsqueda por oportunidades de trabajo profesional que les permitan a los sujetos mejores condiciones de vida es directamente relacionada a las migraciones internacionales. El trabajo profesional se muestra como recurso potenciador de salud psíquica al promover la experiencia de reconocimiento de capacidades del migrante, con efectos en su subjetividad. Por medio del método de investigación psicoanalítica, este artículo discurre sobre el papel del trabajo profesional frente a los impases de la vivencia migratoria. Se discuten los riesgos a la tendencia de patologización social de la migración y se aborda la relación entre migración y potencialidades creativas de la práctica laboral. Se entrevistó a un migrante haitiano y se eligió, también, como material de análisis, el libro intitulado "Sonhos que mobilizam o imigrante haitiano: biografia de Renel Simon" (Sueños que movilizan al inmigrante haitiano: biografía de Renel Simon). En el testimonio constituido a partir del análisis de esas narrativas, se elabora el modo particular con que cada uno de estos sujetos vienen enfrentando sus desafíos en el camino del trabajo de migrar. Se concluye que el trabajo profesional responde a la dimensión de identidad, evaluando el valor de uno mismo, ya que permite al sujeto su inserción social y experiencias intersubjetivas de reconocimiento de las actividades realizadas.

Palabras clave: migración, diáspora haitiana, subjetividad, psicoanálisis, trabajo.

As diásporas sempre estiveram presentes na história das sociedades e associadas, dentre outras motivações, à busca por melhores condições de vida que justificassem o deslocamento de grupos humanos para diferentes partes do planeta (Eberhardt \& Miranda, 2017; Nunes \& Oliveira, 2015). A busca por oportunidades de trabalho profissional que permitam aos sujeitos melhores condições de vida está diretamente relacionada às migrações internacionais, dentre as quais se destaca a diáspora haitiana que, após o abalo sísmico de janeiro de 2010 que agravou a crise social e política no Haiti, ampliou o contingente de saída do país (Gomes, 2017). Nesse contexto, o Brasil consolidou-se como destino estratégico de significativo fluxo migratório que veio em busca, principalmente, de inserção no mercado de 
trabalho formal, contando com benefícios e garantias que este poderia lhe oferecer (Baeninger \& Peres, 2017; Gomes, 2017).

Evidencia-se, assim, nas diásporas, a presença do trabalho, na qualidade de facilitador de acesso a experiências idealizadas. Os migrantes têm se deslocado, prioritariamente, por razões relacionadas com o trabalho (Villen, 2015, 2017), seja por possibilidades de progresso na carreira como é o caso das migrações intencionais, seja por situações em que as crises enfrentadas nos países de origem encaminham os sujeitos à migração como forma de buscar recursos em outros países para o provimento da própria sobrevivência e de seus familiares (Nunes \& Oliveira, 2015). Inexoravelmente, é o exercício laboral, com os recursos por ele possibilitados, o denominador comum dessas distintas equações. Na intersecção entre migração e trabalho, representando os dois extremos da equação, destacam-se, de um lado, a predileção e a atração dos Estados de chegada por migrantes qualificados profissionalmente (Nunes \& Oliveira, 2015; Villen, 2017), em detrimento da acolhida de outros estrangeiros que, não contando com as qualificações profissionais valorizadas, de outro lado, são rechaçados ou, em certos casos, forçados a trabalhos indocumentados (Villen, 2015).

Em estudo sobre migração, desenvolvido em Portugal, Pussetti (2010) alerta para a pecaminosa representação social que associa vulnerabilidade psíquica e condição migrante, deixando desconsideradas as relações entre as precariedades sociais e políticas que dificultam a digna acolhida ao estrangeiro e o sofrimento individual destas decorrentes. Destaca desse modo, a autora, o papel da exclusão social e da discriminação sofridas pelos migrantes nos quadros de adoecimento. Para Pussetti (2010), o processo migratório em si constitui um fator de risco, pois reúne uma série de perdas, as quais pressupõem a necessidade de elaboração de lutos, sendo acompanhado por maior vulnerabilidade a transtornos e perturbações emocionais.

Todavia, o sofrimento que acompanha o necessário luto pelas perdas vividas no processo de se deslocar não deve ser confundido com uma condição de necessária patologização do migrante que, quando universalizada, despreza os recursos psíquicos singulares do sujeito da experiência. É precisamente nesse campo que Knobloch (2015, p. 171) identifica que "a categoria de traumatismo psíquico enquanto uma reação normal a um evento anormal serve para embasar uma nova forma de 'patologia normal', agora identificada diretamente na condição do migrante". Conforme a autora, tal tendência se sustenta em uma lógica que restringe a pluralidade de experiências culturais a um modelo interpretativo único de cunho biomédico que tem no Transtorno de Estresse Pós-Traumático seu paradigma geral a normatizar a patologização deste expressivo grupo de sujeitos. Remetendo-se à proposta de Achotegui - psiquiatra que propôs que os estressores psicossociais da migração levariam a 
uma forma de adoecimento específico, por ele nomeada Síndrome de Ulisses -, Knobloch (2015) considera que a vivência migratória, compreendida a partir dessa categoria psicopatológica, reduz o migrante ao papel de vítima de suas experiências, como único lugar possível a ser ocupado. Restaria, conclui a autora, um sujeito vulnerável que, desenvolvendo problemas psicológicos, deverá ser medicalizado. Há de haver, entretanto, um caminho alternativo, de modo que a legitimação do sofrimento psíquico do migrante, advindo de várias situações e experiências de vida, não deva ser equivalente à patologização da diferença como única forma possível de reconhecimento (Knobloch, 2015) e inserção do estrangeiro (Pussetti, 2010).

Precisamente, nesse contexto, o trabalho profissional afigura-se como precioso recurso potencializador de saúde psíquica ao promover a efetiva experiência de reconhecimento de capacidades e aptidões do migrante, com importantes efeitos sobre sua subjetividade. O trabalho, nesta direção, além de permitir o atendimento das necessidades de subsistência, pode ser fonte de satisfação pulsional pelo exercício prático e pelo reconhecimento de utilidade e beleza por parte de superiores e pares (Dejours, 2011, 2012b). Desse modo, sua importância, não restrita à sobrevivência do corpo físico, estende-se ao campo da economia psíquica e da saúde mental, representando um incomparável recurso de inserção social e intercâmbio cultural. $\mathrm{O}$ acesso à riqueza potencial de tal experiência, é bem verdade, será sempre relativo às condições contextuais e à disponibilidade de recursos de cada sujeito no exercício de suas atividades laborativas.

A tese da centralidade do trabalho para a subjetividade abrange múltiplas dimensões, indo da saúde mental do trabalhador que vê suas competências se ampliarem pelas vivências que o labor possibilita, às transformações da urbe alavancadas pela criação de novas soluções frente aos desafios da realidade, via práticas de trabalho (Dejours, 2012a, 2012b, 2017). Relevância particular possui a prática laboral nas situações em que representa o meio pelo qual um sujeito se inscreve na cultura local, promovendo, para tanto, transformações em si e, em alguns casos, também no grupo e no modus operandi da sociedade de acolhida. Nesse âmbito, trabalho e migração cotejam-se, influenciando-se mutuamente. Desse modo, por meio do método de pesquisa psicanalítica, objetivou-se, nesse estudo, compreender o papel do trabalho profissional frente aos impasses da vivência migratória. A escuta, própria do método de investigação em Psicanálise, é apresentada como fonte de resistência à tendência de patologização social da migração, explorando um campo no qual o ambiente e os recursos singulares do sujeito podem levá-lo a encontrar condições de criação de novos destinos ao sofrimento, evidenciando as potencialidades criativas da prática laboral neste contexto. 


\section{Método}

A presente investigação sustentou-se no método psicanalítico (Dal Forno \& Macedo, n.d.). Entrevistou-se um migrante haitiano, acessado por conveniência, que, quando da primeira entrevistava, encontrava-se no Brasil havia um ano. No intervalo entre a primeira e a segunda entrevistas, este participante conseguiu se empregar, garantindo, assim, um relato em que a vivência laboral na migração esteve presente em dois momentos distintos. Inicialmente, foi enunciada pelo participante como idealização e expectativa acerca do trabalho no país de chegada para, posteriormente, converter-se em prática, que pôde ser avaliada em seus efeitos. O participante assinou o Termo de Consentimento Livre e Esclarecido, autorizando o uso dos dados obtidos em publicações científicas, concedendo entrevistas abertas individuais que foram gravadas em áudio e, posteriormente, transcritas e analisadas. Considerando-se o apreço do participante por futebol, atribuiu-se a ele o pseudônimo "Emmanuel", inspirado em Wilfried Louis Emmanuel Sanon, atacante da Seleção Haitiana de Futebol, na Copa do Mundo de 1974. Como forma de ampliar a leitura do fenômeno em estudo e coerente com o método utilizado, que se propõe ao testemunho elaborado da pesquisa realizada pelos participantes, elegeu-se, também, como material de análise, o livro intitulado "Sonhos que mobilizam o imigrante haitiano: biografia de Renel Simon", de autoria de Margarita Rosa Gaviria Mejía e Renel Simon. Para a realização do presente estudo, assumiu-se como eixo de investigação sobre as migrações a centralidade ocupada pela experiência laboral na subjetividade do migrante.

O material de análise produziu-se por meio da proposta metodológica sustentada nos três tempos do testemunho (Dal Forno \& Macedo, n.d.) intrínsecos ao ofício do pesquisador psicanalítico. O primeiro tempo dá-se quando o pesquisador testemunha a narrativa realizada pelo participante da pesquisa, em que se inclui, além das entrevistas realizadas com Emmanuel, a biografia presente no livro eleito para o estudo. Admite-se, nessa abordagem, que quem faz a pesquisa é o participante, aos moldes da pesquisa feita pelo paciente deitado no divã, cabendo ao pesquisador dirigir o encontro e testemunhar a investigação que o participante realiza. Nesse ponto, cabe ressaltar a intrínseca relação entre este primeiro tempo do testemunho e a condição do pesquisador psicanalítico já ter ocupado o lugar de analisante. Entende-se que este lugar é condição sine qua non para ele, agora, testemunhar a narrativa de um outro. No contexto desta pesquisa, o primeiro exercício de aproximação dos dados se deu por meio da construção de manuscritos acerca de cada uma das entrevistas realizadas bem como da leitura biográfica, preliminares aos encontros de orientação acadêmica. Para tanto, o 
pesquisador leu e releu o material transcrito, escutou novamente os áudios das entrevistas, tomando notas e redigindo uma "Escrita da Transferência". Esse manuscrito inaugural, fruto da escuta das narrativas e da análise da situação transferencial que se estabelecera no contexto das entrevistas e da leitura do livro, foi o material que compôs o objeto de análise inicialmente trabalhado junto ao orientador psicanalista. Precisamente desses encontros constitui-se o segundo tempo da pesquisa psicanalítica, em que, no contexto da orientação, com o orientador psicanalista, o pesquisador procedeu à discussão da análise iniciada e à construção do processo de interpretação dos dados. Durante os encontros de orientação, construíram-se hipóteses interpretativas e elencaram-se elementos que passaram a compor o texto do presente ensaio. $\mathrm{Na}$ sequência do processo de investigação, o terceiro tempo do testemunho amplia o campo ao ofertar à comunidade científica os achados e o trabalho desenvolvido na pesquisa psicanalítica, reconhecendo a importância dos pares na circulação do saber produzido em Psicanálise, principalmente no âmbito acadêmico.

\section{Reconhecimento no trabalho: Caminho de saúde e de criação para o migrante}

A migração tem sido amplamente interpretada como fenômeno coletivo potencialmente traumático (Pussetti, 2010; Knobloch, 2015). Como resultado da necessidade de sucessivos deslocamentos, com sua multiplicidade e fragmentariedade de referências espaciais e simbólicas, ao que se soma a precariedade de acolhida, os migrantes são levados, segundo Pussetti (2010), ao padecimento, que se pode testemunhar nas histórias de relatos de despedaçamento da identidade. A autora assume ser a "invisibilidade social", potencializada pelas contradições políticas migratórias que submetem os sujeitos a condições degradantes, e pelas barreiras burocráticas, a possível produtora de perturbações emocionais podendo levar a patologias mentais. Perversamente, no entanto, circunscreve-se exclusivamente à natureza do sujeito migrante uma suposta fragilidade que o faria suscetível ao adoecimento psíquico. Nesse arranjo, como forma de reconhecimento social, somente resta ao migrante, estranho que deve ser demarcado em sua diferença, o lugar de vítima de sua condição. Adoecido, não teria nada a dizer sobre si, sendo silenciado em sua singularidade e medicalizado em seu sofrimento (Knobloch, 2015).

Na contramão dessa tendência, o presente ensaio constitui-se como um testemunho sobre o processo migratório marcadamente experimentado como satisfatório, realizado por sujeitos que, dispondo de recursos psíquicos potencializados por condições ambientais favoráveis, encontraram no trabalho profissional um campo criativo de reconhecimento e 
ampliação da própria subjetividade, tornando-se capazes de enfrentar as dificuldades inerentes à migração. Tal proposição encontra ancoragem no estudo de Eberhardt e Miranda (2017), que recomendam a realização de pesquisas que abordem o fenômeno migratório na perspectiva do trabalho e da saúde. Mais especificamente, na perspectiva da saúde do trabalhador que, segundo ressaltam os autores, após revisão da literatura latino-americana sobre o tema, representa uma lacuna a ser preenchida por pesquisas de campo.

Encontram-se na obra do psicanalista francês Christophe Dejours os recursos teóricos para se analisar as diásporas humanas, no âmbito das relações existentes entre trabalho, sofrimento, prazer e saúde. Por meio de longa carreira de estudos realizados sobre o trabalho, esse teórico evoluiu em sua compreensão do tema, descobrindo nesta prática humana, vivida em nuances de sofrimento e prazer, importante recurso potencializador da saúde psíquica (Dejours, 2011, 2012a, 2012b). Assim, sinaliza-se, desde já e com grande interesse para o campo das migrações, a possibilidade do sofrimento experimentado pelo sujeito no trabalho, ocasionado pelos constrangimentos impostos pela realidade que resiste às prescrições, não o levarem, necessariamente, à patologia, mas, abrirem a possibilidade de criação de novas soluções e de descoberta de novas capacidades. O trabalho é, para Dejours (2011), um elemento central na promoção do desenvolvimento psíquico e da constituição da identidade.

Nas diásporas, um sujeito migra para ser e esta condição pode ser particularmente favorecida pelo trabalho. A prática laboral está diretamente relacionada aos modos de ser, na medida em que permite ao sujeito descobrir a si no encontro com a alteridade e com os desafios que o trabalho impõe. Migrando para ser, Emmanuel chega ao Brasil. Como motivos de sua migração, refere: "Sai do meu país e vim aqui buscar algo melhor". Trata-se de um jovem que, tendo a oportunidade de concluir os estudos básicos (parte no Haiti e outra parte na República Dominicana), sem, para tanto, ter precisado trabalhar, chega ao ponto de se ver diante da decisão de sair de seu país ou não mais poder seguir progredindo em direção a seus projetos profissionais. Tais particularidades estão diretamente relacionadas ao fato do participante, com 21 anos quando da primeira entrevista, ser filho único do atual casamento de seus pais que, empregados no Haiti, tinham condições econômico-sociais favoráveis aos seus projetos, contrastando com uma população nacional majoritariamente empobrecida. Sua vinda para o Brasil está associada ao propósito de seguir estudando e acessar o ensino superior para garantir sua qualificação profissional. Chama atenção, no entanto, que, mesmo não havendo cobrança explícita que o obrigue a ajudar sua família que ficara no Haiti, vê-se diante do compromisso de devolver os recursos que financiaram seu deslocamento. Conta ele: 
“Terminei meus estudos e vim para cá, para trabalhar e para aprender mais do que sei e falar bem o português e pra poder ir à faculdade. E, lá [no Haiti], passado o terremoto, tu sabe, a coisa tá como mui difícil, pra trabalhar, para fazer tudo. E vim para cá para ajudar a minha família que tá lá e eles me ajudaram para vir para cá. Tenho que devolver o que me emprestaram. É isso."

Emmanuel relata que sua decisão de vir para o Brasil se construiu a partir da recomendação de uma tia paterna que migrara quatro anos antes. Essa, ao falar com seus pais, indicou que haveria a possibilidade de o rapaz seguir seus estudos, caso imigrasse. Em sua fala, Emmanuel mostra que também se convenceu que esse seria o melhor direcionamento para sua vida futura: "Minha mãe e meu pai, falaram com minha tia, que... minha tia tem... quase quatro anos aqui no Brasil. Já faz quatro anos e falou e falou: tem que vir para estudar e trabalhar também, para pagar teus estudos". O participante revela acreditar na palavra dos pais, declarando: "E vi que isso é melhor para mim, isso é o melhor para o meu futuro. Vim para trabalhar e estudar. Tudo isso é melhor. Eu pensei assim”. Acredita na palavra parental, mas também assume sua parcela na decisão: Eu pensei. A mesma referência apresenta-se na forma de nomear a ajuda recebida: Tenho que devolver o que me emprestaram. Assim, Emmanuel tem no empréstimo parental algo que permite seu movimento migratório, mas vem por ter projetos próprios de trabalhar e estudar, de usufruir da oportunidade recebida.

Delineia-se que o fator determinante para sua diáspora foi a palavra dos pais. Certamente, essa palavra não fora pronunciada somente quando do convite da tia que já se encontrava no Brasil e aguardava sua vinda. Trata-se, muito antes, de uma enunciação que estivera presente como fundante de sua subjetividade e que lhe tendo, desde seus tempos primordiais, garantido recursos narcísicos que sustentam sua identidade e seus ideais, ecoara, contemporaneamente, no convite recebido.

No estudo que realiza sobre o narcisismo, Freud (1914/2004, p.99) considera ser "uma suposição necessária a de que uma unidade comparável ao Eu não esteja presente no indivíduo desde o início; o Eu precisa antes ser desenvolvido". Na letra freudiana, encontra-se reconhecido o processo de complexificação subjetiva na relação estabelecida entre o "Eu" que surge e seu objeto primordial (Hornstein, 2009). A constituição do Eu, durante o processo de subjetivação, viabiliza-se, portanto, no campo intersubjetivo com a alteridade com a qual o infante, inicialmente, identifica-se e da qual, posteriormente, diferencia-se. O conceito de alteridade, na síntese esclarecedora de Bleichmar (2010), é definido como o outro humano. É da sucessão de vivências e trocas com esse outro, que lhe investe de afetos, cuidados e 
enunciações, que surgem os elementos e os traços com os quais o novo sujeito se identificará e constituirá sua identidade.

Nesse sentido, encontram-se em Freud (1914/2004) os fundamentos que permitem afirmar que, com a consolidação da unidade narcísica garantidora do surgimento do Eu, viabilizada pelo intenso investimento libidinal voltado ao si mesmo, constituem-se também os ideais do sujeito, introjetados a partir de enunciados identificatórios e de traços do outro primordial, passando a integrar a identidade de um sujeito. Afirma Hornstein $(2009,2018)$ que, do centramento das representações identificatórias possibilitadas pelo narcisismo, o sujeito chega à experiência de identidade e de sentimento de si, sustentado pelas noções de continuidade, de permanência, de coesão. O narcisismo, é, dessa maneira, indubitavelmente decisivo para a estruturação subjetiva, de modo que, da qualidade dos investimentos recebidos e das enunciações introjetadas pelo Eu, dependerá diretamente a disponibilidade de recursos psíquicos ao sujeito para que se lance aos muitos desafios que envolvem ir em busca de seus projetos migratórios, quando é esse o caso.

Nessa perspectiva, o movimento iniciado por Emmanuel expressa o desejo do participante de construir um melhor futuro para si, em que o trabalho se afigura como elemento central. Conta que pretende se formar para trabalhar como contabilista. Relata seus ideais de carreira profissional, enumerando-os: "Contabilidade (...) Cálculo. (...) Desde pequeno, eи queria fazer contabilidade e futebolista". Conta de seu gosto pelo futebol que tem lhe permitido inserir-se em diversos grupos no Brasil, jogando com amigos haitianos de, pelo menos, dois diferentes bairros da capital gaúcha e de uma cidade vizinha, na região metropolitana, além dos colegas de trabalho brasileiros. Pôde-se testemunhar, com particular destaque, a confiança de Emmanuel na efetivação daquilo que viera construir para si no Brasil. Na sua fala, parece seguir ecoando a palavra de seus pais sobre seu futuro e suas potencialidades. Sabe o que veio fazer; sabe quem veio ser no país que o recebeu.

No primeiro encontro com o pesquisador, quando ainda não havia se empregado, o participante demonstrava essa confiança introjetada, ao relatar seus projetos. Em tom sereno e voz calma, contou: "sempre eu digo que vou ter paciência, para que chegue a minha oportunidade". Seu relato revela, assim, um sujeito que migra investido de condições de buscar seus ideais; alguém que possui um projeto de vida que lhe é bastante claro. Deseja se inscrever no país de chegada, trabalhar e aprender a se comunicar eficientemente em português para, então, acessar a faculdade. Entende ele que "tem que falar bem para poder entrar na faculdade". Diferente de tantos outros conterrâneos seus, Emmanuel tem pais que trabalham e se sustentam no Haiti, de modo que não compõe seu projeto trazê-los para morar 
no Brasil, tampouco sustentá-los, mas poder eventualmente ir visitá-los, para o quê precisará dispor de recursos financeiros. Seu compromisso está, desse modo, em produzir recursos exclusivamente para seu próprio sustento. Desvela-se, em seu relato, um senso de autonomia que parece relacionado ao modo como seus pais puderam conduzir sua formação. Em lugar de responsabilizá-lo pela libertação da família da pátria mãe que não provê os seus, puderam capacitar e investir o filho para que ele fosse capaz de ir - em busca de seus projetos - e voltar - para apenas visitá-los. Evidencia-se, assim, a importância do provimento ambiental para o fomento de recursos psíquicos de um sujeito que, autorizou-se construir projetos para si e partir em busca de suas concretizações.

Emmanuel solicitou o visto para vir encontrar a tia no Brasil e se surpreendeu com a rapidez com a qual conseguira o documento. Viaja tendo um destino e a possiblidade de ser acolhido e ajudado. Parece ser oriundo de uma família que conseguiu se organizar para promover sua vinda de forma a preservá-lo de algumas das dificuldades tão comuns aos migrantes que saem de sua terra natal. Nesse sentido, o participante reporta: "minha mãe me falou: 'temos que ver com essa tia', que é irmã do meu pai. Tenho que vir aí, com ela, para que ela me apoie em tudo. E vim aqui para que ela me apoie em tudo”.

Semelhante experiência é relata por Renel Simon em sua biografia. Esse migrante, por sua vez, encontrava-se trabalhando em uma Secretaria Municipal do interior do Estado do Rio Grande do Sul e cursando Relações Internacionais em uma universidade do mesmo município, quando da escrita de sua biografia que se deu em parceria com uma pesquisadora da universidade que frequentava. De seu relato biográfico, destaca-se, particularmente, seu desejo de estudar para progredir, que o sustentou diante das muitas dificuldades da migração, tais como clandestinidade, privação de teto e ter de aprender, de forma autodidata, por meio de dicionários bilingues e assistindo a programas de televisão brasileira, a língua portuguesa, a fim de poder levar a cabo seus projetos de estudo e profissão. Contrastando com Emmanuel, Renel relata sua preocupação com as condições de precariedade em que seus familiares vivem, demandando que envie parte de seu dinheiro, como forma de provimento de sobrevivência. Além disso, esse migrante revela, por meio de sua biografia, que não pretende se estabelecer no Brasil, mas estudar e se formar, fazer uma reserva de dinheiro e, em um prazo de, mais ou menos, quinze anos, retornar ao Haiti para retomar sua vida junto de familiares que lá permaneceram.

Testemunha-se, assim, tanto no relato de vida de Emmanuel, como também no relato biográfico de Renel, evidências de recursos psíquicos que se mostram disponíveis para que esses sujeitos sigam se construindo frente às novas oportunidades que os aproximam da 
realização de seus ideais. Nos seus relatos, destaca-se, de forma especial, o trabalho como fator essencial para as construções a que se propuseram com a migração, dentre as quais se sublinha a construção de si mesmo. O ponto de conexão entre esses dois migrantes, cujas histórias de vida são aqui testemunhadas na forma de ensaio, é, portanto, o trabalho, particularmente naquilo que o exercício laboral possibilita a subjetividade. Ambos parecem encontrar no trabalho profissional uma via de reconhecimento para suas existências e, por consequência, para a realização de si mesmos.

Nessa perspectiva, entende-se que, quando migra, especialmente em se tratando das migrações que visam a busca por melhores condições de vida, um sujeito lança-se a uma experiência de trabalho que responde, simultaneamente, a duas dimensões. Na primeira, há o labor para o provimento do sustento que implicará em fazer frente aos desafios da própria realidade laboral, em que pesem todos os contrastes presentes, adaptando-a e transformandoa, recriando-a onde se fizer necessário e possível. Na segunda dimensão, está propriamente outra exigência de trabalho, qual seja, o trabalho de migrar, que envolve a (re)criação de si mesmo, em meio a uma nova realidade, com as potencialidades subjetivantes do exercício laboral, que põem em movimento a identidade do migrante. Trata-se, assim, de uma exigência de trabalho elaborativo daquilo que é despertado no psiquismo do sujeito pelo movimento que realiza.

Nessa dimensão, desfere-se certeira a referência de Dejours (2012a) a Freud, no que tange à compreensão da pulsão como sendo uma exigência de trabalho do somático ao psíquico. Trabalho esse compreendido por Freud como ação e como pensamento, isto é, como elaboração qualitativa da sensação que é iniciada no corpo e ganha representação no psiquismo. Nesse sentido, destaca Dejours $\left(2012^{\mathrm{a}}\right.$, p. 66) que, "se desenvolvimento psíquico há, sob o efeito da pressão pulsional, este desenvolvimento é decorrente de um trabalho cuja forma primeira é, sem sombra de dúvida, a elaboração". Nesse trabalho de ampliação do psiquismo, em que se entende estar contemplada a migração, no trabalho que exige ser realizado pelo sujeito, compreende-se com Dejours (2012a, p. 70), da leitura que realiza da proposição freudiana de pulsão, que "a alma seria essencialmente o resultado de uma transformação proveniente do interior do corpo pelo viés de um trabalho cuja forma típica seria a elaboração". Seu importante avanço, ao situar o trabalho produzindo o sujeito, encontra, portanto, fundamento na letra freudiana quando esclarece sua compreensão de que não se trataria da alma, isto é, do psiquismo a produzir a elaboração da excitação que se iniciaria no corpo, mas que seria a própria elaboração que produziria o psiquismo. Certamente esse conjunto de afirmações coaduna-se perfeitamente aos primórdios da vida, quando a 
subjetividade está a se formar, simultaneamente à estruturação do psiquismo (Bleichmar, 2010). No entanto, o psiquismo e a subjetividade seguem seu caminho de complexificação e expansão mediante as experiências que um sujeito realiza ao longo de sua existência. Trata-se, portanto, de considerar o potencial subjetivante do trabalho, mormente quando, em se tratando de um migrante trabalhador, soma-se a exigência elaborativa do trabalho de migrar.

É bem verdade que as bases do Eu se solidificam nos primeiros anos de vida de um sujeito. Todavia, o psiquismo segue aberto a seu entorno, não se circunscrevendo às experiências identificatórias iniciais, por mais importantes que tenham sido. Segundo considera Hornstein (2013, p.65), "a identificação não é um feito único, que ocorre de uma vez e para sempre (...). Enquanto houver vida, haverá trajeto identificatório”. Condizente com essa leitura, Lancman (2011) entende a constituição da identidade como um processo que se desenvolve ao logo de toda a vida do sujeito, estando vinculada à noção de alteridade. Considera serem as relações cotidianas as que possibilitam a construção da identidade individual e social, por meio das trocas materiais e afetivas, que levam o sujeito a constituir sua singularidade no contexto das diferenças. Segundo a autora, para o adulto, o espaço do trabalho é palco privilegiado dessas trocas com a alteridade. Reconhece, assim, o trabalho "como mediador central da construção, do desenvolvimento, da complementação da identidade e da constituição da vida psíquica. $\mathrm{O}$ trabalho permite o confronto entre mundo externo e mundo interno do trabalhador" (Lancman, 2011, p 41).

A mobilização subjetiva ocasionada pelo trabalho, na medida em que coloca em questão a identidade, possui, de acordo com Dejours (2011, 2012a, 2012b), ação transformadora sobre o sujeito trabalhador. Nesse sentido, Sznelwar (2011, p.48) sublinha como parte significativa dos estudos desse psicanalista do trabalho, a "relação dialética existente entre o que o sujeito já seria e o que ele se torna pelo confronto com a realidade do trabalho". Tal proposição é particularmente pertinente no presente contexto de estudo, em que sujeitos migram para ser, podendo consegui-lo por meio do trabalho externo e interno que se veem desafiados a realizar.

Esse desafio que, no presente estudo, chamou-se de trabalho de migrar, e que se dá simultaneamente ao exercício profissional remunerado, não se processa, entretanto, sem algum padecimento. Nesse sentido, Gomes (2017), situa que o ato de migrar leva à inevitável ruptura com o universo simbólico de origem do migrante, provocando-lhe perdas, mudanças e transformações sociais e subjetivas. A autora destaca que essas experiências, dentre tantas outras (des)construções psíquicas e sociais, podem, por um lado, promover sofrimento, e, por outro, possibilitar novos rumos e renovadas criações de si. Tal estado de coisas está presente 
no relato de Emmanuel sobre tomar mais distância da família como parte do processo de migrar:

“Um pouco senti estranho, por causa da minha família, mi pai, mi mãe, meus primos, primas, meu tio, tia, tudo isso. E... cada vez que me pego pensando como ficar mais perto, é mais tranquilo, lá... Mas, aí, não penso muito, porque tem poucos anos para avançar no meu futuro, e não penso muito nisso, porque eu penso que eu era muito pequeno no início e que agora sou adulto e fico tranquilo".

Entende-se que compara a experiência de, quando mais jovem, ter saído de casa para estudar na República Dominicana com a experiência de migrar para o Brasil para construir sua vida profissional, agora como adulto. Seu relato indica que o migrante busca dentro de si os recursos necessários para suportar a saudade que a distância lhe provoca. Escolhe pensar no futuro, no qual vislumbra uma vida melhor, que poderá ser alcançada por meio do trabalho e do estudo. Sobre o sentimento provocado pela distância dos seus, nomeia como "doloroso". Faz um longo silêncio após tal classificação. Perguntado sobre como faz para lidar com esse sentimento, refere que sai para caminhar pela cidade quase todos os dias, ouvindo música com fones de ouvido. Sua força está na confiança que deposita na palavra dos pais: "Minha mãe, meи pai me falou, me falou, me disse: 'tu tem que ir lá para viver e pra construir uma vida melhor'. E, de repente, eu digo que sim, sem pensar nada". Confia na palavra dos pais que o sustenta nessa busca por um futuro com mais opções.

$\mathrm{Na}$ segunda entrevista, Emmanuel conta que importantes mudanças aconteceram na sua vida, dentre as quais destaca o fato ter iniciado um trabalho com carteira assinada. Seguia residindo com a tia que lhe acolheu. Sobre o que mudou, declara: "Aconteceu muita coisa para mim. É diferente quando eu tô trabalhando e ajudando a mí tia que eu tô morando ẩ'. O participante estava se comunicando com muito mais fluência e disponibilidade do que demonstrara no pretérito. No seu tom de voz, percebia-se certo orgulho do que contava, sobremaneira no que tangia a estar podendo ajudar com o sustento da casa. Ele parecia se reconhecer em sua capacidade e potência de realizar aquilo a que se propusera com a migração. Estava conseguindo colocar em prática seus projetos de inserção na comunidade brasileira e qualificação de sua capacidade de comunicação na língua local, os quais lhe permitirão voltar aos bancos escolares para seguir se aprimorando.

Ter conseguido um emprego formal, que lhe dá certas garantias de direitos e, também, recursos financeiros para acessar bens e serviços, testemunha uma subjetividade com recursos 
e potencialidades para a concretização de seus desejos. Perguntado sobre sua experiência de trabalho, referiu que "É um trabalho tranquilo, não tem muito esforço. Como que voy dizer? É só isso...”. Não era o trabalho que idealizava realizar, mas via nele a possibilidade de seguir progredindo para acessar outras oportunidades. No que tange às relações com os colegas, relatou que estava tudo bem, que conversava com seus colegas, os quais lhe perguntavam e se interessavam por seu país, e para os quais mostrava vídeos e fotografias, anteriores ao terremoto. Relatou, também, as diferenças gastronômicas entre o Brasil e o Haiti. Seu ambiente de trabalho, pelas relações que estabelece com seus pares, revela-se um espaço de consideração e acolhida à alteridade que sua estrangeiridade representa:

"Eu converso com ellos sobre mi país, sempre me pergunta se tem playa, se tem lugar bonito, sobre essas coisas. Eu disse pra ellos “sim”. Eu busquei pela internet. Ellos acham maravilhoso. (...) Eles sempre tão perguntando como fazem as comidas... De lá para cá, é muito diferente. Sim, é muito diferente. Tão perguntando se tem tudo de lá como aqui, se tem churrasco. Sim, lá também tem. Lá, também, tem churrasco, pero não é como aqui. Não tem como muita gente, não. Tem que comprar num mercado. Não tem gente que faz em casa. Também pergunta se tem cerveja. Si, tem, pero diferente, diferente o nome, diferente botella."

A narrativa de Emmanuel sobre as diferenças existentes entre o Haiti e o Brasil também ilustram como é possível que elas sejam nomeadas e propiciem espaços de trocas. $\mathrm{O}$ churrasco, a cerveja não são iguais, mas são as diferenças que promovem tanto o diálogo com os brasileiros como a possibilidade de conhecer, experimentar e gostar de outras comidas, costumes e tradições. Mais do que aberto ao aprendizado de uma nova língua, Emmanuel dá testemunho da curiosidade que potencializa a construção de seus projetos de autonomia.

Em se tratando de Renel, sua biografia revela um migrante que buscou em diversos empregos no Brasil a compatibilidade com seu projeto de seguir estudando para obter o diploma de Ensino Superior. Em um dos empregos que teve, em uma indústria de alimentos, sentia dores nos braços, devido ao trabalho repetitivo. A essa dificuldade, somou-se uma situação de discriminação, que o levou a pedir demissão. No entanto, ao falar do trabalho, remete-se a um ditado popular de seu país: "trabalho é liberdade” (Mejía \& Simon, 2015, p. 43). Mesmo tendo enfrentado dificuldades com a prática exercida e sofrido perseguição por ser estrangeiro, entende que o exercício laboral permite projetar sua independência e se aproximar de seus ideais. Quando da redação de sua biografia, esse migrante trabalhava no 
Centro de Referência de Assistência Social da prefeitura de sua cidade, ajudando na acolhida e no encaminhamento da documentação de outros migrantes que chegavam na região de cobertura do serviço. Expressa grande satisfação com o trabalho que realiza, relatando sentir "grande prazer em ajudar seus conterrâneos" (Mejía \& Simon, 2015, p. 45).

O trabalho, pelas vivências de reconhecimento que pode oportunizar, representa singular lastro às representações identificatórias do sujeito. Indubitavelmente, tal potência não pode ser desprezada no contexto da migração, em que as questões envolvendo a identidade são particularmente postas em xeque pelo encontro com a alteridade da outra cultura. Nessa seara, os estudos de Dejours oferecem conceitos substanciais para a análise do trabalho colocado em ação nas diásporas humanas. Dejours (2011, 2012a, 2012b) considera todo trabalho como sendo humano, uma vez que sua realização pressupõe um sujeito que se aproprie daquilo que está prescrito e, a partir de sua interpretação, efetivamente invente o trabalho. Explicitamente, o autor propõe como definição que o "trabalho é a atividade manifestada por homens e mulheres para realizar o que ainda não está prescrito pela organização do trabalho" (Dejours, 2011, p. 78). O caráter de criação necessário para que o trabalho aconteça, em vista das particularidades de cada contexto e situação concreta, está, indiscutivelmente, considerado nessa compreensão. Desse modo, ao afirmar a inegociável centralidade da subjetividade na prática laboral, Dejours (2011, 2012a, 2012b) conceitua o trabalho como sendo o hiato existente entre a concepção da tarefa e aquilo que efetivamente o trabalhador executa mediante sua interpretação. Tal ação laboral somente poderá se dar a partir das condições subjetivas de um trabalhador.

Dejours $(2011,2012 b)$ considera, assim, que, para que haja trabalho, será necessária a mobilização subjetiva daquele que irá se empenhar para inventar aquilo que ainda não existe. Esclarece o autor que, por mais espontânea que possa ser tal mobilização, ela não deixa de ser extremamente frágil, dependendo sua manutenção da dinâmica existente entre a contribuição que o sujeito oferta à organização do trabalho e aquilo que ele espera receber em termos de retribuição. Segundo propõe Dejours (2011, 2012b), a retribuição esperada pelo sujeito não se restringe ao concreto da remuneração, mas mais importante é a retribuição simbólica, que recebe em termos de reconhecimento pelo trabalho realizado. Esse reconhecimento, garantido pelo julgamento de utilidade, realizado verticalmente por superiores, ou pelo julgamento de estética, proferido horizontalmente pelos pares, refere-se à atividade realizada. Entretanto, destaca Dejours $(2011,2012 b)$ que o reconhecimento pela qualidade do trabalho realizado pode se inscrever na esfera da personalidade, gerando, dessa maneira, ganhos no registro da 
identidade, uma vez que "a retribuição simbólica conferida pelo reconhecimento pode fazer sentido em relação às expectativas subjetivas quanto à realização de si mesmo".

Sem que pese menosprezo aos indiscutíveis benefícios da prática laboral para inserção comunitária do migrante, de particular interesse no campo da migração revela-se a inoxidável contribuição do trabalho profissional à identidade e à saúde psíquica do sujeito, quando considerados os ganhos oportunizados pelo reconhecimento. Sobremodo, quando se tem em conta, conforme apontado, a indiscriminada e inaceitável patologização do sofrimento inerente às diásporas. É no campo da psicodinâmica do trabalho que se encontra reconfortante alento. Situa Dejours (2011, p 88) que "a construção do sentido do trabalho pelo reconhecimento - premiando o indivíduo quanto a suas expectativas com respeito à sua realização pessoal (edificação da identidade no campo social) - pode transformar o sofrimento em prazer". Desse modo, os constrangimentos experimentados pelo migrante, manifestados como sofrimento, podem, graças ao reconhecimento das contribuições subjetivas ao trabalho, oportunizados pela retribuição simbólica a essa prática, abrir espaço para o prazer da criação em lugar do adoecimento.

Todavia, alerta Dejours (2011, p.91) que, "se a dinâmica do reconhecimento está paralisada, o sofrimento não pode mais ser transformado em prazer, não pode mais encontrar sentido: só pode gerar acúmulos que levarão o indivíduo a uma dinâmica patogênica de descompensação psíquica ou somática". Daí decorre a inestimável relevância de não se frustrar o sujeito migrante naquilo que ele busca criar por meio do trabalho que realiza. Com a contribuição que oferece na forma de trabalho, mobiliza sua subjetividade que, no reconhecimento da qualidade da atividade realizada, descobre-se, também, reconhecida, aceita, acolhida em sua singularidade. Dessa maneira, a hospitalidade, preconizada por Derrida (2003) como oferta de acolhimento incondicional ao estrangeiro, mostra-se coerente com o campo de uma prática laboral na qual a abertura à criatividade contempla a subjetividade por meio de práticas de reconhecimento às contribuições singulares.

Por fim, conforme situa Gomes (2017), a partir do estudo realizado com migrantes haitianos, as rupturas ocasionadas pela migração possibilitam aos sujeitos que procedam à criação de novos sentidos e posicionamentos subjetivos. Com Dejours, acrescenta-se que tais transformações e criações, acredita-se, possam ser produzidas por meio do trabalho. No testemunho elaborado a partir da escuta e análise das narrativas de Emmanuel e Renel, ensaiase um reconhecimento do modo particular com que cada um destes sujeitos tem, criativamente, enfrentado seus próprios desafios no caminho do trabalho de migrar. 


\section{Considerações Finais}

A migração humana, fenômeno histórico e demasiadamente contemporâneo, associada à busca, por parte de um sujeito, de melhores condições de vida, tem costumeiramente no trabalho profissional uma meta central a direcionar esforços. Como possibilidade de sustento, principalmente em se tratando das migrações relacionadas a crises, tais como a diáspora haitiana, o trabalho, não raramente, é apresentado como justificativa para o enfrentamento de grandes dificuldades, que vão dos riscos envolvidos nas travessias até os desafios nas tentativas de inserção nos países de destino.

No contraste existente entre a migração qualificada - caracterizada pela facilitação de ingresso nos territórios e pelo incentivo e atração por parte dos governos a certo tipo de migrantes - e a migração de crise - costumeiramente relacionada à clandestinidade e à consequente precarização do trabalho -, existe um sujeito que migra para ser. Compete, desse modo, a esse importante ator, com os recursos psíquicos e ambientais de que pode dispor, o enfrentamento do sofrimento inerente ao processo de deslocamento e ao encontro com a alteridade no país de destino. Entretanto, como parte da tendência atual de patologização do sofrimento, da qual não escapa a migração, que já se vê contemplada, até mesmo, na proposição de uma categoria psicopatológica específica, retira-se do centro da questão o sujeito da experiência migratória, desprezando-o em suas condições singulares de construir soluções e o reduzindo ao lugar de vítima de sua condição. Entende-se, todavia, que o trabalho profissional, pelas vivências de reconhecimento da qualidade das atividades realizadas assumidas pelos sujeitos como reconhecimentos de si próprios, não só trazem ganhos identitários como podem operar como vias transformadoras de sofrimento em prazer, prestando incomparável auxílio ao migrante em seu trabalho de migrar para outra cultura.

Assim, a prática profissional revela-se em sua inegável relevância para a subjetividade do migrante. O trabalho, estando normalmente relacionado aos motivos do deslocamento, enquanto encaminha o atendimento das necessidades básicas de subsistência, viabiliza o contato imediato com os nativos e com a cultura local, em um exercício de existência no encontro com a alteridade. Esse mesmo trabalho responde à dimensão identitária, aquilatando o valor de si mesmo, na medida em que possibilita ao sujeito sua inserção social e vivências intersubjetivas de reconhecimento pelas atividades realizadas.

Na contramão dos discursos homogeneizantes da experiência migratória, com suas previsões patologizantes do sofrimento, Emmanuel e Renel têm podido, por meio do reconhecimento no trabalho, converter sofrimento em prazer. Seus relatos são testemunho do 
trabalho profissional como precioso recurso de saúde e potencialidade no caminho singular do trabalho de migrar. Particularmente preocupante, todavia, é a situação dos migrantes indocumentados que, confrontados pelas burocracias de ingresso nos países de destino, veemse submetidos a trabalhos precarizados nos quais a condição de reconhecimento, estando negada, traz prejuízos à identidade e à saúde psíquica. Nesse contexto, a hospitalidade, na forma de reconhecimento às criações dos migrantes trabalhadores e, também, como acolhida por meio de práticas que oportunizem a devida documentação e viabilizem o trabalho digno, favorece à inserção social e permite dar ao sofrimento inerente à migração um encaminhamento no campo da saúde, evitando as fórmulas psicopatológicas generalizantes que excluem o sujeito.

Este estudo buscou lançar luz sobre a singularidade da experiência migratória de dois sujeitos, particularmente no que se refere ao papel do trabalho profissional como via de acesso ao outro e a si mesmo. Limitações podem ser reconhecidas na especificidade dessa proposta, na medida em que a busca pelo necessário aprofundamento da experiência compromete a amplitude de um estudo sobre populações. Considerando-se a atualidade e a complexidade da temática, recomenda-se a realização de outras pesquisas em que estejam contemplados sujeitos de outras nacionalidades e com experiências diversas daquelas exploradas neste manuscrito.

\section{Referências}

Baeninger, R., \& Peres, R. (2017). Migração de crise: A migração haitiana para o Brasil. Revista Brasileira de Estudos Populacionais, 1(34), 119-143. doi:10.20947/S0102$3098 \mathrm{a} 0017$

Bleichmar, S. (2010). La subjetividad en riesgo. Buenos Aires: Topía Editorial.

Dal Forno, C., \& Macedo, M. M. K. (n.d.). Pesquisa Psicanalítica: Da transferência com a Psicanálise à produção do Ensaio Metapsicológico. Revista Psicologia: Teoria e Pesquisa. Manuscrito submetido para publicação.

Dejours, C. (2011). Addendum: da psicopatologia à psicodinâmica do trabalho. In S. Lancman \& L. Sznelwar (Orgs.), Christophe Dejours: da psicopatologia à psicodinâmica do trabalho (pp. 57-123). Brasília: Paralelo 15/ Rio de Janeiro: Editora Fiocruz.

Dejours, C. (2012a). Trabalho Vivo: Sexualidade e trabalho (Vol. 1). Brasília: Paralelo 15.

Dejours, C. (2012b). Trabalho Vivo: Trabalho e emancipação (Vol. 2). Brasília: Paralelo 15. 
Dejours, C. (2017). Prefácio. In C. Dejours (Org.), Psicodinâmica do Trabalho: Casos Clínicos (pp. 6-10). Porto Alegre: Dublinense.

Derrida, J. (2003). Anne Dufourmantelle convida Jacques Derrida a falar da hospitalidade. São Paulo: Escuta.

Eberhardt, L. D., \& Miranda, A. C. (2017). Saúde, trabalho e imigração: Revisão da literatura científica latino-americana. Saúde em debate, 41(n.spe.2), 299-312. doi:10.1590/010311042017 S 225

Freud, S. (2004). À Guisa de Introdução ao Narcisismo. In L. A. Hanns (Ed. \& Trad.), Escritos sobre a Psicologia do Inconsciente (Vol. 1, pp. 95-131). Rio de Janeiro: Imago. (Obra original publicada em 1914)

Gomarasca, P. (2017). Direito de excluir ou dever de acolher? A migração forçada como questão ética. REMHU: Revista Interdisciplinar de Mobilidade Humana, 25(50), 11 24. doi:10.1590/1980-85852503880005002

Gomes, M. A. (2017). Os impactos subjetivos dos fluxos migratórios: Os haitianos em Florianópolis (SC). Psicologia \& Sociedade, 29, 1-11. doi:10.1590/18070310/2017v29162484

Hornstein, L. (2009). Narcisismo: Autoestima, identidade, alteridade. São Paulo: Via Lettera.

Hornstein, L. (2013). Las encrucijadas actuales del psicoanálisis: subjetividad y vida cotidiana. Buenos Aires: Fondo de Cultura Económica.

Hornstein, L. (2018). Ser analista hoy. Buenos Aires: Paidós.

Knobloch, F. (2015). Impasses no atendimento e assistência do migrante e refugiados na saúde e saúde mental. Psicologia USP, 26(2), 169-174. doi:10.1590/01036564D20140015

Lancman, S. (2011). Apresentação: O mundo do trabalho e a psicodinâmica do trabalho. In S. Lancman \& L. Sznelwar (Orgs.), Christophe Dejours: Da psicopatologia à psicodinâmica do trabalho (pp. 31-43). Brasília: Paralelo 15/ Rio de Janeiro: Editora Fiocruz.

Mejía, M. R. G., \& Simon, R. (2015). Sonhos que mobilizam o imigrante haitiano: Biografia de Renel Simon. Lajeado: Editora da Univates.

Nunes, J. W., \& Oliveira, S. D. (2015). Evidências da construção da figura do imigrante qualificado no Brasil: Uma leitura a partir da Lei $n^{\circ}$ 6.815/80. In A. M. N. Vasconcelos \& T. Botega (Orgs.), Política migratória e o Paradoxo da globalização (pp. 33-51). Porto Alegre: EDIPUCRS. 
Pussetti, C. (2010). Identidades em Crise: Imigrantes, emoções e saúde mental em Portugal. Saúde e Sociedade, 19(1), 94-113. doi:10.1590/S0104-12902010000100008

Sznelwar, L. (2011). Introdução: Sobre estes textos da psicodinâmica do trabalho, algumas reflexões. In S. Lancman \& L. Sznelwar (Orgs.), Christophe Dejours: da psicopatologia à psicodinâmica do trabalho (pp. 45-54). Brasília: Paralelo 15/ Rio de Janeiro: Editora Fiocruz.

Villen, P. (2015). O trabalho forçadamente indocumentado e institucionalmente silenciado: A imigração dos "periféricos emergenciais" para o Brasil. Revista da ABET, 14(2), 186198.

Recuperado

de

http://www.periodicos.ufpb.br/ojs/index.php/abet/article/view/27949/15018

Villen, P. (2017). A face qualificada-especializada do trabalho imigrante no Brasil: Temporalidade e flexibilidade. Caderno CRH, 30(79), 33-50. doi:10.1590/s010349792017000100003

\section{Endereço para correspondência}

\section{Cristiano Dal Forno}

Av. Ipiranga, 6681 prédio 11 sala 80, Porto Alegre - RS, Brasil. CEP 90619-900

Endereço eletrônico: cristiano.forno@pucrs.br

\section{Rita de Cássia dos Santos Canabarro}

Av. Bento Gonçalves, 9500 prédio 43815 sala 226, Porto Alegre - RS, Brasil. CEP 91509-900

Endereço eletrônico: canabarro.rita@gmail.com

\section{Mônica Medeiros Kother Macedo}

Av. Ramiro Barcelos, 2600, Porto Alegre - RS, Brasil. CEP 90035-003

Endereço eletrônico: monicamkm@icloud.com

Recebido em: 05/04/2019

Reformulado em: 08/10/2019

Aceito em: 26/10/2019

\section{Notas}

* Psicólogo. Doutor em Psicologia. Professor do Curso de Psicologia da Escola de Ciências da Saúde e da Vida da Pontifícia Universidade Católica do Rio Grande do Sul.

** Psicóloga. Mestra em Psicologia Social e Institucional. Psicóloga da Universidade Federal do Rio Grande do Sul.

*** Psicanalista. Doutora em Psicologia. Professora do Programa de Pós-Graduação Psicanálise: Clínica e Cultura da UFRGS. Bolsista Produtividade em Pesquisa do CNPq - Nível1D. 
Cristiano Dal Forno, Rita de Cássia dos Santos Canabarro, Mônica Medeiros Kother Macedo

Este artigo de revista Estudos e Pesquisas em Psicologia é licenciado sob uma Licença Creative Commons Atribuição-Não Comercial 3.0 Não Adaptada. 